\title{
Electric Vehicle Charging Stations Coverage: A Study of Slovenia
}

\author{
Klemen PRAH*, Mark KMETEC, Matjaž KNEZ
}

\begin{abstract}
To promote the penetration of electric vehicles (EVs), it is of great importance to plan and construct charging stations rationally. In this sense, the state of Slovenia's charging station coverage was analysed. Using discrete and network geographic information system (GIS) models, with ArcGIS software, the density of electric vehicle charging stations (EVCSs), geographic distribution, nearness along a street network, and clustering analyses were performed. A survey conducted among Slovenian users of EVs supported the GIS analysis. It was found out that the distribution of EVCSs has an east-northeast to west-southwest directional trend. Only $13 \%$ of EVCSs are accessible from the nearest motorway at a distance of 500 meters or less. An insight into intrinsic clustering structure revealed 11 clusters of EVCSs from which the most distinct is the cluster on the area of Ljubliana. The scientific contribution of the research is in the integration of GIS, spatial analysis and the results of a survey to study the coverage of EVCSs in a certain region. Spatial analyses are carefully selected, and, in complementarity, give a comprehensive picture of EVCSs coverage. The research is important for further spatial planning of EVCSs.
\end{abstract}

Keywords: electric vehicle charging stations; geographic information systems; Slovenia; spatial analysis

\section{INTRODUCTION}

Around the world, new technologies that require us to adapt to them are emerging from day to day. An electric vehicle $(\mathrm{EV})$ is one such technology. They are both economical and ecological vehicles that get their power from rechargeable batteries inside the car [1]. The main disadvantage of these vehicles is recharge-related problems [1]. For this reason, auto execs must predict not only business opportunities but also available resources, such as electric vehicle charging stations (EVCSs) [2]. Looking at one known example, the demise of EV1, the first mass-produced and purpose-designed electric vehicle of the modern era, was allegedly caused also by insufficient electric infrastructure [3]. One of essential solutions for efficient and more extensive use of electric cars is therefore a proper distribution of EVCSs.

With the rapid emergence of new and innovative forms of passenger transport, the location intelligence is more important than ever, managed and delivered by a sophisticated geographic information systems (GIS) [2]. With the help of sophisticated GIS, the main goal of this study is to determine the coverage of EVCSs in Slovenia. Such coverage means the spatial characteristics of electric vehicles charging stations to understand where and also why these are deployed. The coverage is also population weighted and certain travel patterns of the population are taken into consideration.

To cross-reference the characteristics of EVCSs coverage with consumer preferences, the study is supported by a survey conducted among Slovene EV users. The purpose of the whole study is to contribute to easier decision-making regarding further measures to rollout, deploy and improve EVCS infrastructure.

The primary limitations regarding the survey are the limited time frame in which it was carried out and the subjectivity of peoples' personal opinions, which can be dynamic and vary over time. Another limitation is the statistical sample of the survey, which may not represent the whole population.

\section{STATE-OF-THE-ART}

The siting (i.e., location) of a major facility has long been a subject of interest [4]. The research focused on the siting of EVCSs has received much attention in recent years, and it is known that EVCS site selection is a multiple-criteria evaluation problem $[1,5]$. Many papers describe research aimed at studying and optimising the siting of EVCSs. The authors have used different types of decision-making methods, such as mixed-integer linear programming (MILP)[6], genetic algorithm [7], particle swarm optimisation [8], maximal coverage location model [9], arc-based location optimisation model [10], analytic hierarchy process (AHP) [11], and others.

General siting analysis with GIS began in the 1970s, for example with Dobson [12], who utilised several nominal groups to determine weights to apply for each siting criterion [4]. In the field of transport, the GISs research appeared relatively late, only in the late $1980 \mathrm{~s}$ [13]. Specifically, the transport sector has become very multidisciplinary, and GISs have been positioned as an ultimate technology for the integration of information [13]. The process of combining data layers, each weighted by some factor, can now be easily accomplished in most GISs [4].

GIS-based Multi-Criteria Decision Analysis (MCDA) techniques are commonly used for different spatial decision problems in literature, such as the selections of wind power plant sites, municipal landfill sites etc., but there is still a gap regarding the selection of EVCS sites [1]. One of recent comprehensive examples of the selection of EVCS sites by GIS is from Erbas and co-authors [1]. There, after the selection of EVCS sites, the indicators were prioritised using a fuzzy Analytical Hierarchy Process (AHP), and potential EVCS sites were ranked by using Techniques for Order Preference by Similarity to Ideal Solution (TOPSIS).

Geographic information systems were also used by other authors to identify and determine EVCSs. For example, Guler and Yomralioglu [11] integrated GIS and Multi-Criteria Decision Making (MCDA) methods for finding suitable locations of EVCSs. Zhou et al.[5] combined GIS with MCDA methods to provide a practical model for location decision of photovoltaic charging stations. Pagany et al. [14] used GIS in a user- and destination-based approach for locating EVCS. Shepero and Munkhammar [15] developed a spatial Markov chain 
model to model the charging load of EVs in cities. Kontou et al.[16] studied the linkage between EV charging network coverage and charging opportunity using GPS travel data. In contrast, GIS tools in some studies were used more in a marginal sense, for example, only to present locations of candidate and optimal EVCSs [17].

In Slovenia, a gap remains in research about coverage with EVCSs from a geographical point of view. We know that $38 \%$ of people from the studied sample in the research [18] has a very positive attitude towards low emission vehicles (LEV) purchasing, and they are planning to buy one in the near future. Another $42 \%$ of the total sample has a positive attitude toward LEVs, even if they are not sure about buying one in the near future. Therefore, the knowledge about coverage with EVCSs in Slovenia would enable further research work to determine the optimal distribution of charging stations. In this regard, geographical science can play an important role, because it is well-equipped for a deep understanding of alternativefuel prospects [19].

\section{METHODOLOGY}

A simple map of EVCSs for Slovenia is available on the website Polni.si [20]. In our research, we are tackling a sophisticated methodology for analysing and presenting Slovenia's coverage of EVCSs, focussing on the use of GIS technology. GISs are computer-based systems for the capture, storage, manipulation, display, and analysis of geographic information. Their core ability is the integration of information. Integration will have a reasonably high probability of producing insight that would otherwise be missed if the spatial models were not integrated within the GIS [21]. Newly uncovered insight with GIS plays an important role in decision making.

In our research, two classes of GIS models are relevant. Firstly, discrete models, according to which discrete entities like EVCSs populate space. Secondly, the network model to represent topologically connected linear entities, i.e., roads, which influence the EVCSs. It is probably not necessary to emphasise that the effectiveness of GIS analysis depends on the quality of spatial data.

In the GIS analysis of Slovenia's coverage with EVCSs, we placed significant emphasis on spatial analysis techniques and GIS tools. Spatial analysis (or geospatial analysis, or spatial data analysis) refers to the problemsolving aspect of GIS [22] and represents only one context within the broader concept of geographic information analysis that also comes up with other contexts: spatial data manipulation, spatial statistical analysis and spatial modelling [23]. Geographic information analysis is concerned with investigating the patterns that arise as a result of processes that may be operating in space [23]; geo-visualisation has a critical place in such analysis [24].

For the analysis, we prepared all data in the form of digital vector layers in a shapefile format. All GIS analyses were performed using ArcGIS for Desktop software, version 10.8.1, and ArcGIS Pro, version 2.4. In a meaningful sequence, we performed the following analyses, focused initially on municipalities. To find out a relationship between EVCSs and certain characteristics of municipalities, we calculated Pearson's correlation coefficient [25]. To investigate the relationship with the number of population more deeply, we calculated the polynomial regression [26].

We focused further on Slovenia as a whole to find out the characteristics of EVCSs within a single dataset. We estimated the density characteristics of EVCSs and therefore created a continuous density surface, which is based on a sophisticated variation on a basic kernel density estimation [23]. Secondly, we calculated the mean centre, the central feature, and the standard deviational ellipse of EVCSs to determine their geographic distribution.

As the above analyses hinted at a relationship between EVCSs and motorways, we examined this relationship in more detail. As the analysis considering the straight-line distance has an inherent flaw when dealing with networks, we modelled a street transportation network and analysed the nearness of EVCSs along motorways. Used algorithm of Origin-Destination Cost Matrix analysis is based on Dijkstra's algorithm of the shortest path tree [27].

For establishing a statistical foundation and a statistical confidence level for pattern analysis of EVCSs, we upgraded the study with two types of analysis. First is calculation of Average nearest neighbour index, and second is Ordering Points to Identify the Clustering Structure (OPTICS) [28]. We used the first to find out if there is a statistically significant level of clustering of EVCSs, and we used the second to detect areas where EVCSs are concentrated and to explore the intrinsic clustering structure. Each fragment of analysis is described in more detail in the section 4.

To obtain empirical data, we helped with a qualitative survey, the purpose of which was to obtain data on the coverage of Slovenia with charging stations. For the systematic collection of data, we used online survey questionnaire, which contained 22 questions, of which 17 were closed-ended and 5 open-ended questions. The questionnaire was validly completed by 25 respondents, owners of electric cars, of which 21 respondents were men. $60 \%$ of respondents were between 41 and 60 years old, and $36 \%$ were between 21 and $40.32 \%$ of respondents have completed vocational high school and the other $32 \%$ university degree. Respondents come from all twelve statistical regions of Slovenia, most from Central Slovenia (44\%) and Upper Carniola (24\%). We are aware that the statistical sample of the survey does not represent the whole population; however, it is an important complement to GIS analysis of this study.

\section{RESULTS}

Slovenia has 308 public EVCSs, with a total of 637 charging connectors to charge electric cars [20]. Auxiliary EVCSs (i.e., those for motor homes and private ones) are not considered here. At the end of 2016, there were only 137 public EVCSs in Slovenia [29]. Considering the fact that Slovenia covers 20273 square kilometres, there are only 0,015 EVCSs per square kilometre on average. There are three super-charging stations of the Tesla company in Slovenia among the mentioned 308 public EVCSs. They are located at the rest stop in Dogoše near Maribor, at the Hotel Mons in Brdo and at the Ravne rest stop in the Primorska region [30].

The uneven spatial distribution of EVCSs can be seen in Fig. 1, showing 308 public EVCSs in Slovenia. Higher 
concentrations can be observed in the area of major cities, such as Ljubljana, Maribor, Kranj, Koper, etc. Higher concentrations can also be observed along the roads of higher categories ( 1 and 2), but are present also along the roads of lower categories (3 and 4). Furthermore, the presence of EVCSs can be observed in tourist resorts (e.g., Bled, Podčetrtek, Rogaška Slatina, etc.) and along the
Adriatic coast. A higher concentration of EVCSs along the border with Austria leads us to suspect that Austria is more developed in terms of use of electric vehicles than, for example, Croatia. These are rough estimates, while a systematic analysis of the distribution of EVCSs in Slovenia follows below.

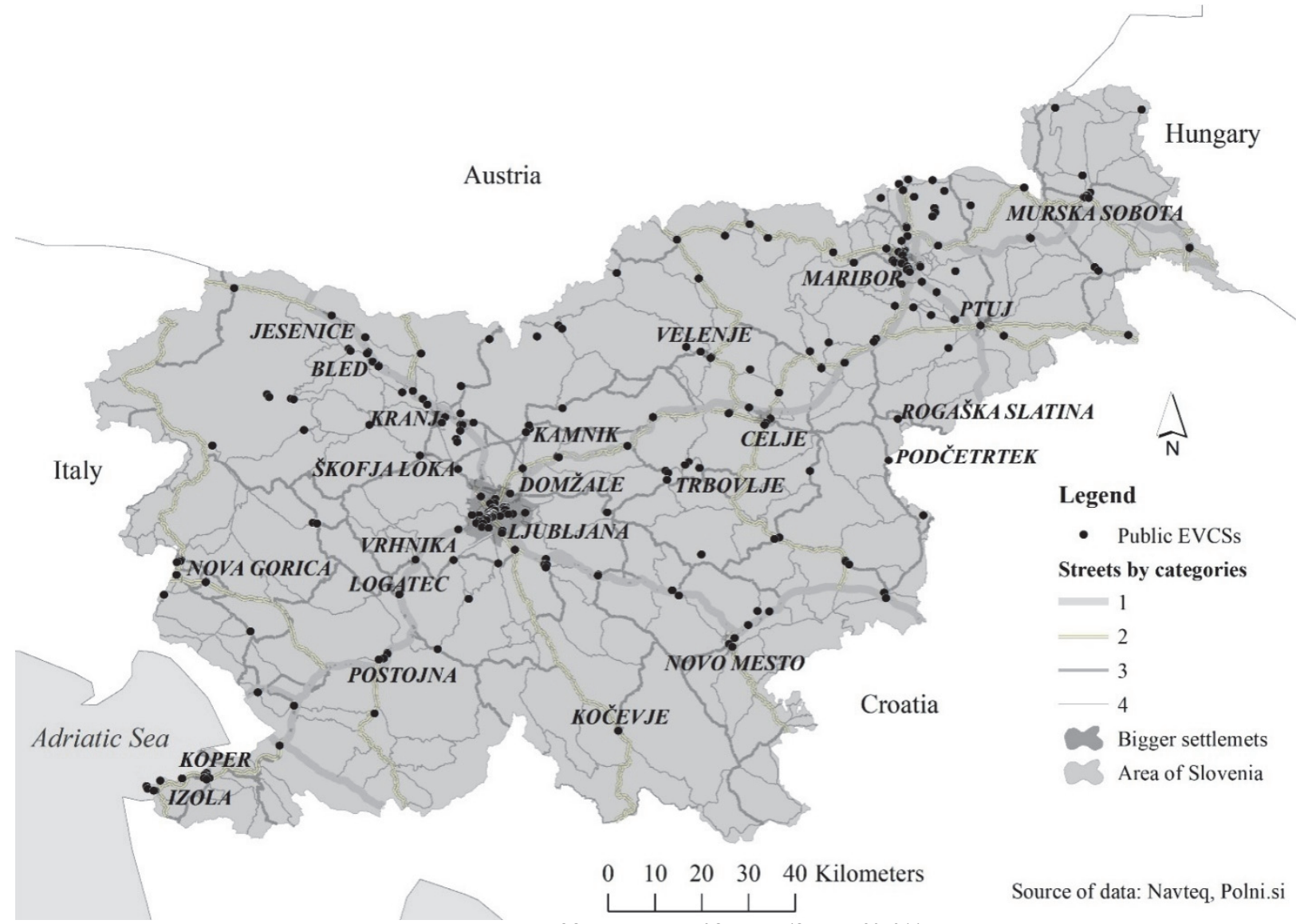

Slovenia is divided into 212 municipalities, of which 11 have urban status. Many EVCSs, 68 of 308 to be precise, are concentrated in the City Municipality of Ljubljana, whose centre is Ljubljana, the largest and capital city of Slovenia (Fig. 2). The City Municipality of Maribor in the north-eastern part of Slovenia has the second highest number of EVCSs, i.e., 24. The central city is Maribor, the second-largest city in Slovenia. Then follow 14 municipalities with 5-7 EVCSs, 35 municipalities with 2-4 ECVSs, 49 municipalities with 1 EVCS, and 113 municipalities with no EVCSs.

To find the relationship between the number of EVCS and certain characteristics of municipalities, regarding population, labour migrations and urban status, we calculated Pearson's correlation coefficient [25]. We only found strong positive relationship with the variable of number of population, namely 0,95 (Tab. 1). To investigate this relationship more deeply, we calculated the polynomial regression [26], which is a non-linear relationship between the independent and dependent variables. $R$ Square of 0,93 confirms strong relationship between both variables, with outstanding citymunicipalities of Ljubljana and Maribor having the highest number of both population and EVCSs (Fig. 3).

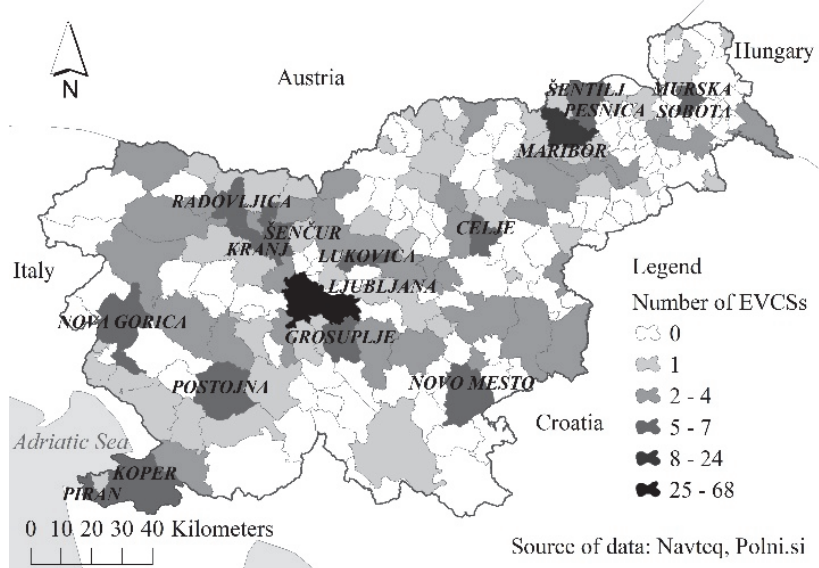

Figure 2 Number of EVCSs per municipality

Table 1 Pearson's correlation coefficients between number of EVCSs and certain characteristics of municipalities (Source of data [20,32])

\begin{tabular}{|c|c|}
\hline Characteristics of municipalities & Number of EVCS \\
\hline Population 2019 & 0,95 \\
\hline Population density 2019 & 0,65 \\
\hline Urban status & 0,49 \\
\hline $\begin{array}{c}\text { Working in the municipality of residence } \\
2018\end{array}$ & 0,40 \\
\hline Labour migration index 2018 & 0,31 \\
\hline
\end{tabular}




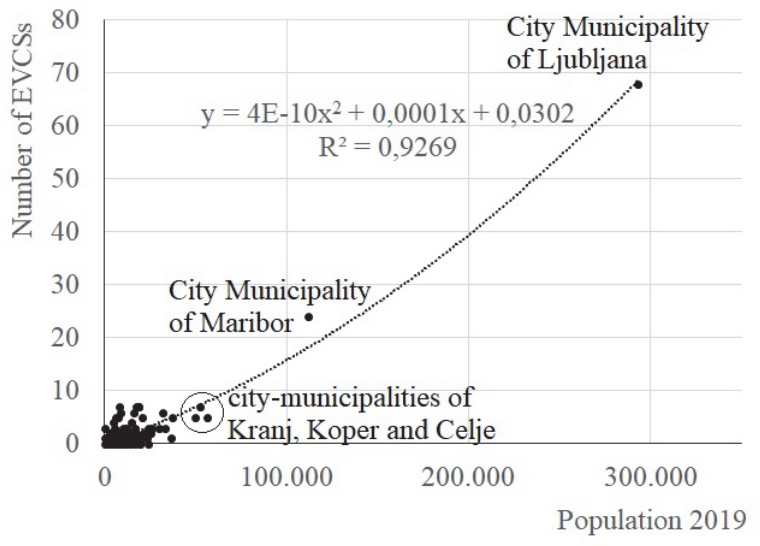

Figure 3 Polynomial regression model of $2^{\text {nd }}$ degree between population and number of EVCSs

The respondents to the survey estimated that Slovenia is relatively well covered by EVCSs, but these EVCSs are not quite enough for their needs ( $68 \%$ of respondents). In particular, Ljubljana and Maribor are well equipped with EVCSs, while Novo Mesto and Kranj are not. Generally, respondents describe a lack of EVCSs outside the two major cities of Slovenia. However, the situation in Slovenia does not lag behind the neighbouring countries $(80 \%$ of respondents have experience with EVCSs abroad).

\subsection{Density of EVCSs in Slovenia}

So far we have found out how EVCSs are spatially distributed in Slovenia regarding municipalities and their certain characteristics. But to find out how EVCSs are grouped in whole area of Slovenia, we estimated the density below. With the data of EVCSs we created a density surface, which is a raster image. The calculation is based on a sophisticated variation on a basic kernel density estimation, resulting in continuous density estimate surface [23]. We chose cell size of 1 square kilometre, which created good enough resolution, and the search radius, the so-called kernel bandwidth, of 30 kilometres, which is within appropriate range for Slovenian dimensions. The output values for kernel density represent the predicted density values (Fig. 4).

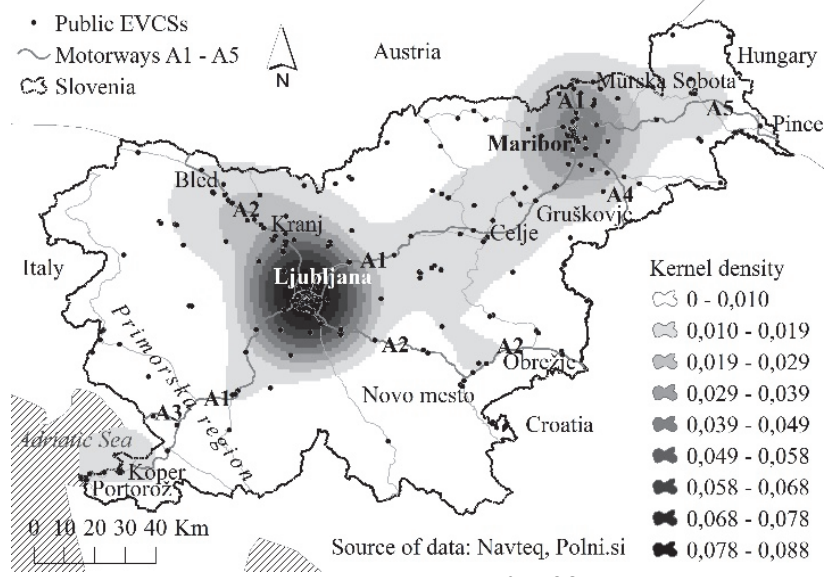

Figure 4 Kernel Density of EVCSs

Two hot-spots are very well noticeable. The more outstanding one is in central Slovenia on the area of Ljubljana, where the maximum values range between
0,078 and 0,088 EVCSs per square kilometre, and the second one is in north-east part of Slovenia on the area of Maribor, where the maximum values range between 0,039 and 0,049 EVCSs per square kilometre. Both hot-spots can be explained with two biggest settlements of Slovenia, although there is quite big difference between them regarding the density of EVCSs. Further, an increased density of EVCSs is recognized in the diagonal from northeast part of Slovenia to the coastal south-west part, but resulting only slightly above average. If we look closely, we will not overlook another diagonal extending from north-west to south-east, with similar slightly accentuated range.

The first mentioned diagonal coincides mainly with A1 "Slovenika" arm of so called "Slovenian Motorway Cross", including also kernels of some major Slovenian cities, such as Murska Sobota (along motorvay A5), Celje and coastal cities. The second mentioned diagonal coincides with A2 "Ilirika" arm of "Slovenian Motorway Cross", with more outstanding north-west arm, where Kranj is with similar density values as Maribor. South-east arm of considered diagonal is barely noticeable and is caused by slight kernel on the area of Novo mesto.

\subsection{Geographic Distribution of EVCSs in Slovenia}

Regarding characteristics of EVCSs within a single dataset, we measured the distribution of EVCSs, that is, the distance between features within a dataset. It contributed to our perception and to our overall understanding of pattern and clustering of EVCSs. We included three calculations to determine geographic distribution of EVCSs in Slovenia: the mean centre, the central feature, and the standard deviational ellipse.

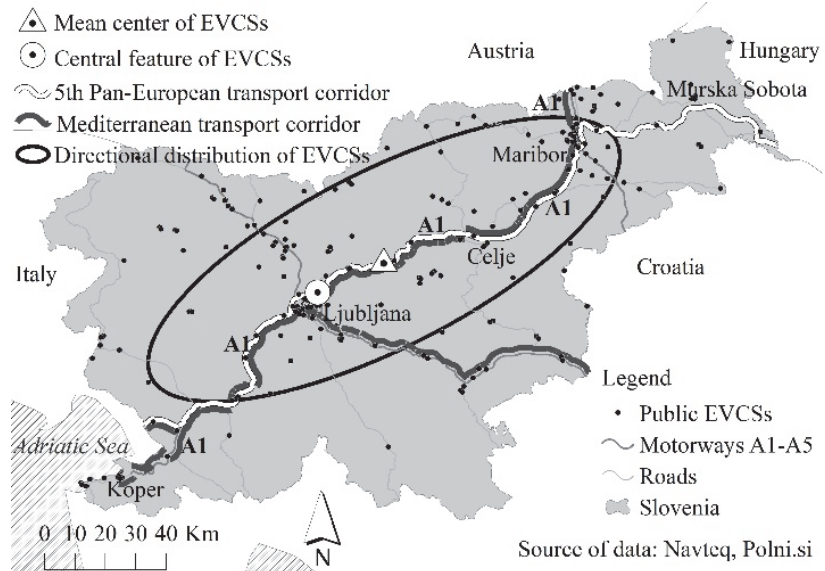

Figure 5 Mean centre, central feature and standard deviational ellipse of EVCSs

The mean centre of EVCSs is the location represented by the mean $x$-coordinate value and the mean $y$-coordinate value for all EVCSs features in the study area [33]. As a result, the mean centre of EVCSs in Slovenia is located at the coordinates 487988,65 east longitude and 116490,40 north latitude, having regard to geographic coordinate system D48/GK. This location is in the municipality of Lukovica, along the motorway arm A1 Slovenika, approximately 30 kilometres (considering the Euclidean distance) away from the centre of the capital city Ljubljana in north-east direction, and 8 kilometres north of the geometric centre of Slovenia in Vače (Fig. 5). Especially 
considering the geometric centre, we can say that the mean centre of EVCSs is really centrally positioned in Slovenia.

We are also interested in the central EVCS in Slovenia. We made a calculation of totalling the distance from each EVCS to every other EVCS for this purpose. As a result, the EVCS with the lowest total distance to all other EVCSs, i.e. 16812,57 kilometres, is located on the north-northeast outskirts of the Municipality of Ljubljana (Fig. 5). This is the most accessible EVCS regarding Euclidean distance and its location is in the capital municipality.

We have already pointed out the diagonal direction of Slovenian motorways and locations of major settlements. In this regard, we are interested in directional trend of EVCSs, which can be shown with an ellipse, with the axes oriented to match the orientation of the EVCSs. The ellipse is referred to as the standard deviational ellipse, since the method calculates the standard distance deviation, or simply the standard distance separately for the $x$ coordinates and the $y$-coordinates from the mean centre [22]. As a result, the standard distance of $x$-axis is 85,75 kilometres and for $y$-axis it is 29,04 kilometres. The angle of the rotation of the ellipse is $63,05^{\circ}$, which means an ENE-WSW (east-northeast to west-southwest) directional trend (Fig. 5). An elongated ellipse tells us that the EVCSs follow the trend of A1 motorway, which coincides with a very busy $5^{\text {th }}$ Pan-European transport corridor, as well as with Mediterranean Corridor of Trans-European Transport Network (TEN-T). As the ellipse is not especially thin, the EVCSs are distributed also elsewhere, but to a lesser extent.

\subsection{Analysis of Nearness along a Road Network}

So far we have considered Euclidean distance in various types of analysis. But the analysis using straightline distance has an inherent flaw when dealing with streets or other types of networks [22]. Namely, the distance measurements may cross areas that the network does not access. To overcome that flaw, we performed a network analysis of the nearness along a network type. We were interested in the nearness of EVCSs along roads of the highest level, i.e., motorways. Motorways represent high impact on the environment; therefore favourable conditions for use of battery electric vehicles, which also includes the proximity to EVCSs, are important. In [34] authors found out that there is a lack of willingness to accept long detours in terms of leaving the motorway to recharge the battery.

We modelled a street-network dataset using the Network Analyst extension of ArcGIS for Desktop 10.8.1 software. Then we performed a network analysis of the Origin-Destination Cost Matrix type. This uses a multipleorigin, multiple-destination algorithm based on Dijkstra's algorithm of the shortest path tree [27].

The results (Tab. 2, Fig. 6) show that only 40 EVCSs, i.e. $13 \%$ are accessible from the nearest motorway at a distance of 500 meters or less, and the other 33 EVCSs, i.e. $10,7 \%$ are accessible at a distance between 500 and 1000 meters. The other 235 EVCSs, i.e. $76,3 \%$ are accessible at a distance greater than 1 kilometre, of which as many as 93 EVCSs at a distance greater than 5 kilometres.

The EVCSs can be noticed along all Slovenian motorways (Fig. 6). Given the total motorway length of
533,3 kilometres, the EVCSs that are accessible from the nearest motorway at a distance of 0,5 kilometre or less, would be spaced every 13,3 kilometres if spaced evenly. Given that the electricity for EV driving can last from 85 to 160 kilometres generally [35], this would be acceptable.

Table 2 Nearness of EVCSs to the closest motorway

\begin{tabular}{|c|c|}
\hline Network distance / Meters & Number of EVCSs \\
\hline up to 500 & 40 \\
\hline $501-1000$ & 33 \\
\hline $1001-2000$ & 56 \\
\hline $2001-5000$ & 86 \\
\hline more than 5000 & 93 \\
\hline Total & 308 \\
\hline
\end{tabular}

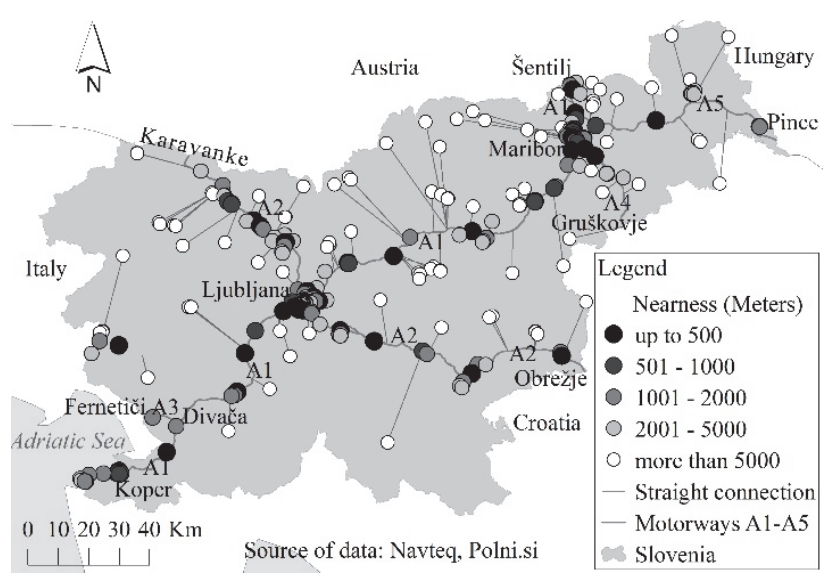

Figure 6 Nearness of EVCSs to the closest motorway

The same was confirmed by our respondents, since no one mentioned any lack of EVCSs along Slovenian motorways. This tells us that, for the current situation, there are enough EVCSs along the motorways. However, given that electric cars are becoming increasingly powerful and will be able to travel distances equivalent to those that internal combustion cars can, their use will also increase on motorways. In this case, it will be necessary to analyse where to install new EVCSs along the motorways. Spatial GIS analysis is indispensable here.

\subsection{Analysing Patterns of EVCSs}

So far we have identified certain spatial patterns regarding EVCSs in Slovenia. With a view to examining this in more detail, we wanted to establish a statistical foundation and a statistical confidence level for pattern analysis of EVCSs. Therefore we performed two types of analysis. First is the calculation of Average nearest neighbour index, and second is Density-based clustering. In the latter analysis, we chose the method Ordering Points To Identify the Clustering Structure (OPTICS) [28].

To find out if the locations of EVCSs are closer together than would be expected with a random distribution, we calculated the Average nearest neighbour index. It expresses the ratio of the observed distance divided by the distance from the hypothetical data [22]. We are dealing with 308 EVCSs spread across Slovenia. As a result, the observed mean distance between each EVCS and its nearest neighbour is 2082 metres, the mean distance for random distribution is 4666 metres, and the nearest neighbour index as a ratio is 0,45 . Given that the ratio is much smaller than 1 , it can be said with great reliability 
that the observed distribution of EVCSs is clustered. Given the $z$-score of $-18,6$, there is less than $1 \%$ likelihood that this clustered pattern could be the result of random chance.

The advantage of the next, the OPTICS method is that it computes an augmented cluster-ordering of the database objects. Such augmented cluster-ordering contains information which is equivalent to the density-based clusterings corresponding to a broad range of parameter settings. The cluster-ordering can also be represented graphically which allows us an interactive exploration of the intrinsic clustering structure [28]. The settings for our OPTICS analysis were as follows: Minimum Features per Cluster $=5$; Search Distance $=5 \mathrm{~km}$; Cluster Sensitivity $=$ 1. The Cluster Sensitivity parameter determines how the shape (both slope and height) of peaks within the reachability plot (Fig. 7) are used to separate clusters. Our choice of the lowest possible value for Cluster Sensitivity parameter treats only the steepest, highest peaks as a separation between clusters, resulting in a lower number of clusters [36].

As a result, we detected 11 clusters, which together contain 174 EVCSs (Fig. 7). The remaining 134 EVCSs represent noise. Most distinct is the cluster on the area of Ljubljana, with characteristic valley on the Reachability plot, which implies that a short distance needs to be travelled from one EVCS to the next. With other words, low reachability distances and low valley on the plot indicate dense cluster of EVCSs on the area of Ljubljana.
The other clusters are less distinct. Clusters with greater range of reachability order and quite low reachability distances can be noticed also on the areas of Maribor and Slovene Riviera, which can be explained with quite high number of EVCSs and quite dense clusters. The latter area is a seaside tourist destination, bordered to the north by Italy and to the south by Croatia. Other, less distinct clusters were also identified. Two clusters coincide with a north-west arm of motorway A2 Ilirika, i.e. Kranj and Bled. Kranj is the fourth largest city in Slovenia, located approximately 20 kilometres north-west of Ljubljana. Bled is a popular tourist destination in the Upper Carniola region and in Slovenia as a whole, attracting visitors from abroad too.

Three more, less distinct clusters can be exposed, i.e. Nova Gorica, Šentilj and Celje. Nova Gorica is a town in western Slovenia, on the border with Italy, joined in a common trans-border metropolitan zone. Šentilj lies in the north-east of Slovenia and borders Austria. The motorway A1 Slovenika, and the Pan-European Corridor $X$ runs through Šentilj. Both border cities Nova Gorica and Šentilj are known for gambling tourism. Celje is the third-largest town in Slovenia. The Maribor-Ljubljana motorway (A1) runs past Celje. The Celje cluster consists of seven EVCSs, as shown in Fig. 7. They are all in the uppermost section of the plot, which means higher Reachability distances and therefore less dense cluster.

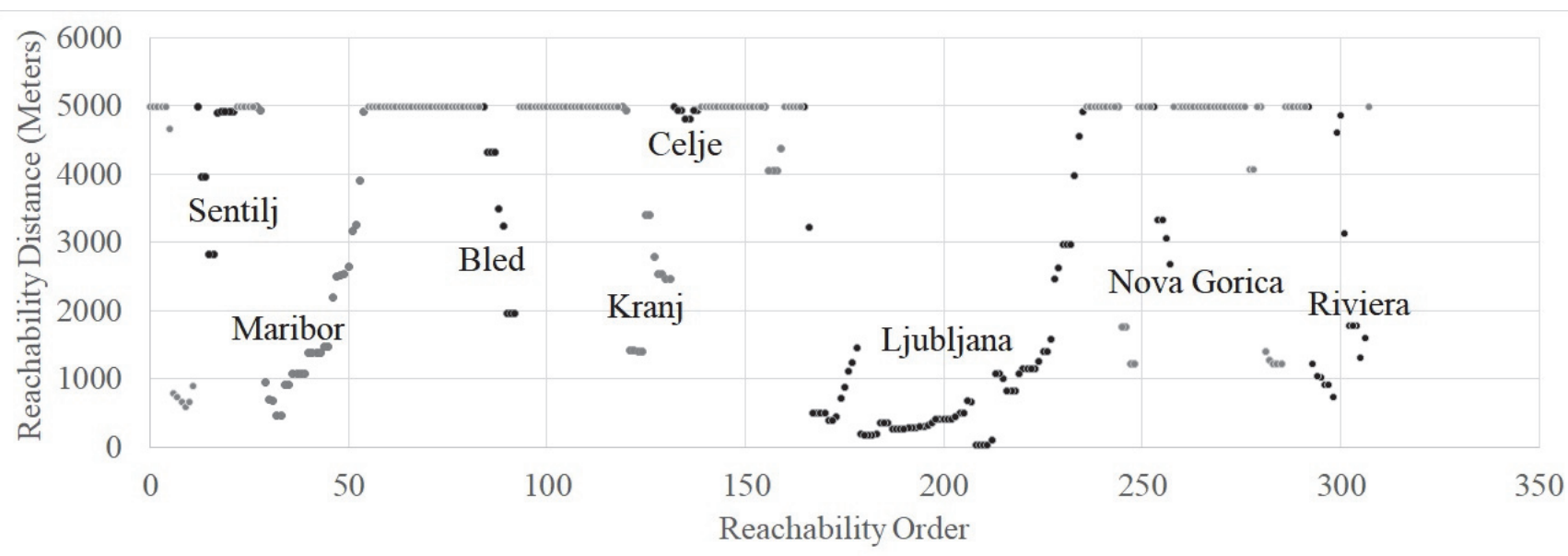

Figure 7 Reachability plot of EVCSs

\section{CONCLUSION}

In this paper we proposed an approach to study the coverage of Electric vehicles charging stations (EVCSs) on the case of Slovenia. Coverage is the mean of spatial characteristics of EVCSs to understand where, and also why these are deployed. The main advantage of our approach is a combination of GIS technology, spatial analysis and a survey results.

We demonstrated an approach that encompasses the following analysis in a meaningful sequence. We focused on the municipalities initially and calculated Pearson's correlation coefficient and polynomial regression between EVCSs and certain characteristics of municipalities. In the following, we focused on Slovenia as a whole. We created a continuous density surface, and calculated the mean centre, the central feature, and the standard deviational ellipse of EVCSs. To exceed an inherent flaw of straightline distance we created a street network and performed an Origin-Destination Cost Matrix analysis. Finally, for establishing a statistical foundation and a statistical confidence level for pattern analysis, we calculated an Average nearest neighbour index, and performed the analysis of Ordering Points to Identify the Clustering Structure (OPTICS). To cross-reference the characteristics of EVCSs coverage with consumer preferences, we conducted a short survey among EV users.

As a conclusion, we would point out four factors that we found to have an important impact on the coverage of EVCSs. These factors are the size of the city in terms of population, the nearness to the motorway, the touristic area, and the border area. Regarding OPTICS analysis, 11 clusters were detected, from which the most distinct is that on the area of Ljubljana. No distinct cluster of EVCSs is 
found in some parts of Slovenia, namely in the Dolenjska and Notranjska regions bordering Croatia, in the Carinthia region bordering Austria, in the Alpine high mountains region, and in the less developed Pomurje region bordering Hungary mainly. Our respondents from the survey exposed that the lack of EVCSs in Slovenia is the most significant not only in smaller towns and remote places but also in tourist destinations. They pointed out two tourist places Izola at the seaside and Kranjska Gora in the Alpine region.

We are aware that the four factors mentioned above would need further in-deep analysis to determine the extent to which each factor contributes to the phenomenon. A Geographically weighted regression analysis might be appropriate for this purpose and let it remain as an opportunity for further research.

A larger set of analysis types could not be avoided in the research. In confirmation to this statement let us compare, as an example, the kernel density estimation and the OPTICS analysis. The first gives us the result about the location of hot spots and higher density areas, which is useful to visualize a point pattern. But to point out clusters of the meaningful criteria, and to explore the intrinsic clustering structure, the methodology of OPTICS analysis was needed.

The scientific contribution of the research is in the integration of GIS, spatial analysis and the results of a survey to study the coverage of EVCSs in certain region. Spatial analyses are carefully selected, and, complementarily, give a comprehensive picture of EVCSs coverage, which is important in spatial planning. The approach may also serve as an idea for similar research in other regions of different levels. However, it would make sense to include other factors in further research, in particular the social sciences that influence the coverage of EVCSs.

\section{REFERENCES}

[1] Erbaş, M., Kabak, M., Özceylan, E., \& Çetinkaya, C. (2018). Optimal siting of electric vehicle charging stations: A GISbased fuzzy Multi-Criteria Decision Analysis. Energy, 163, 1017-1031. https://doi.org/10.1016/j.energy.2018.08.140

[2] Elliott, C. (2018, February 20). As Personal Car Ownership Falls, Automaker Innovation Rises.

[3] ArcNews. (2013). Keeping Electric Vehicles Alive. Esri. https://www.esri.com/about/newsroom/arcnews/keepingelectric-vehicles-alive/

[4] Church, R. L. (2002). Geographical information systems and location science. Computers \& Operations Research, 29(1), 541-562. https://doi.org/10.1016/S0305-0548(99)00104-5

[5] Zhou, J., Wu, Y., Wu, C., He, F., Zhang, B., \& Liu, F. (2020). A geographical information system based multi-criteria decision-making approach for location analysis and evaluation of urban photovoltaic charging station: A case study in Beijing.Energy Conversion and Management, 205, 112340. https://doi.org/10.1016/j.enconman.2019.112340

[6] Bian, C., Li, H., Wallin, F., Avelin, A., Lin, L., \& Yu, Z. (2019). Finding the optimal location for public charging stations - a GIS-based MILP approach.Energy Procedia, 158, 6582-6588. https://doi.org/10.1016/j.egypro.2019.01.071

[7] Pan, L., Yao, E., Yang, Y., \& Zhang, R. (2020). A location model for electric vehicle (EV) public charging stations based on drivers' existing activities. Sustainable Cities and Society, 59, 102192. https://doi.org/10.1016/j.scs.2020.102192

[8] Zhang, Y., Zhang, Q, Farnoosh, A., Chen, S., \& Li, Y. (2019). GIS-Based Multi-Objective Particle Swarm
Optimization of charging stations for electric vehicles. Energy, 169, 844-853.

https://doi.org/10.1016/j.energy.2018.12.062

[9] Dong, G., Ma, J., Wei, R., \& Haycox, J. (2019). Electric vehicle charging point placement optimisation by exploiting spatial statistics and maximal coverage location models. Transportation Research Part D: Transport and Environment, 67, 77-88. https://doi.org/10.1016/j.trd.2018.11.005

[10] Csiszár, C., Csonka, B., Földes, D., Wirth, E., \& Lovas, T. (2020). Location optimisation method for fast-charging stations along national roads. Journal of Transport Geography, 88, 102833. https://doi.org/10.1016/j.jtrangeo.2020.102833

[11] Guler, D. \& Yomralioglu, T. (2020). Suitable location selection for the electric vehicle fast charging station with AHP and fuzzy AHP methods using GIS.Annals of-GIS, 26(2), 169-189. https://doi.org/10.1080/19475683.2020.1737226

[12] Dobson, J. E. (1979). A regional screeining procedure for land use suitability analysis. Geographical Review, 69(2), 224-234. https://doi.org/10.2307/214965

[13] Thill, J.-C. (2000). Geographic information systems for transportation in perspective. Transportation Research Part C: Emerging Technologies, 8(1), 35-12. https://doi.org/10.1016/S0968-090X(00)00029-2

[14] Pagany, R., Marquardt, A., \& Zink, R. (2019). Electric Charging Demand Location Model - A User- and Destination-Based Locating Approach for Electric Vehicle Charging Stations. Sustainability, 11(8), 2301. https://doi.org/10.3390/su11082301

[15] Shepero, M. \& Munkhammar, J. (2018). Spatial Markov chain model for electric vehicle charging in cities using geographical information system (GIS) data. Applied Energy, 231, 1089-1099. https://doi.org/10.1016/j.apenergy.2018.09.175

[16] Kontou, E., Liu, C., Xie, F., Wu, X., \& Lin, Z. (2019). Understanding the linkage between electric vehicle charging network coverage and charging opportunity using GPS travel data. Transportation Research Part C: Emerging Technologies, 98, 1-13. https://doi.org/10.1016/j.trc.2018.11.008

[17] Xu, J., Zhong, L., Yao, L., \& Wu, Z. (2018). An interval type-2 fuzzy analysis towards electric vehicle charging station allocation from a sustainable perspective. Sustainable Cities and Society, 40, 335-351. https://doi.org/10.1016/j.scs.2017.12.010

[18] Knez, M., Jereb, B., \& Obrecht, M. (2014). Factors influencing the purchasing decisions of low emission cars: A study of Slovenia. Transportation Research Part D: Transport and Environment, 30, 53-61. https://doi.org/10.1016/j.trd.2014.05.007

[19] Kuby, M. (2006). Prospects for geographical research on alternative-fuel vehicles. Journal of Transport Geography, 14(3), 234-236. https://doi.org/10.1016/j.jtrangeo.2006.02.008

[20] Polni.si. (n.d.). Zemljevid polnilnih postaj. Retrieved from http://polni.si/

[21] Fotheringham, S. (2000). GIS-Based Spatial Modelling: A Step Forwards or a Step Backwards? Spatial Models and GIS: New Potential and New Models, 21-30.

[22] Allen, D. (2009). GIS tutorial II: Spatial analysis workbook. ESRI Press.

[23] O'Sullivan, D. \& Unwin, D. (2010). Geographic Information Analysis (2nd ed.). Wiley.

[24] Smith, M. J., Goodchild, M. F., \& Longley, P. A. (2018). Geospatial Analysis: A Comprehensive Guide to Principles Techniques and Software Tools (6th digital ed.).

[25] Pearson, K. (1895). Note on regression and inheritance in the case of two parents. Proceedings of the Royal Society of London, 58, 240-242. https://doi.org/10.1098/rspl.1895.0041 
[26] Gergonne, J. D. (1974). The application of the method of least squares to the interpolation of sequences. Historia Mathematica, 1(4), 439-447. https://doi.org/10.1016/0315-0860(74)90034-2

[27] Dijkstra, E. W. (1959). A note on two problems in connexion with graphs. Numerische Mathematik, 1, 269-271. https://doi.org/10.1007/BF01386390

[28] Ankerst, M., Breunig, M. M., Kriegel, H. -P., \& Sander, J. (1999). OPTICS: ordering points to identify the clustering structure. ACM SIGMOD Record, 28(2), 49-60. https://doi.org/10.1145/304181.304187

[29] Pavšič, G. (2017, September 25). Električni avti v Sloveniji: Koliko jih potrebujemo leta 2030, da država uide penalom iz Bruslja? SiolNET.

[30] Tesla. (n.d.). Supercharger. Retrieved from https://www.tesla.com/supercharger

[31] NAVTEQ. (2008). NAVTEQ NAVSTREETS Street Data. [Data set]. NAVTEQ.

[32] Statistical Office of the Republic of Slovenia. (n.d.).STAGE, Geospatial data.

Retrieved from https://www.stat.si/StatWeb/en

[33] Mitchell, A. (2009). The ESRI Guide to GIS Analysis: Spatial measurements \& statistics. Esri Press.

[34] Philipsen, R., Schmidt, T., van Heek, J., \& Ziefle, M. (2016). Fast-charging station here, please! User criteria for electric vehicle fast-charging locations. Transportation Research Part F: Traffic Psychology and Behaviour, 40, 119-129. https://doi.org/10.1016/j.trf.2016.04.013

[35] Yang, S. N., Cheng, W. S., Hsu, Y. C., Gan, C. H., \& Lin, Y. B. (2013). Charge scheduling of electric vehicles in highways. Mathematical and Computer Modelling, 57(11), 2873-2882. https://doi.org/10.1016/j.mcm.2011.11.054

[36] ArcGIS Pro. (n.d.). How Density-based Clustering works. Esri. Retrieved from https://pro.arcgis.com/en/pro-app/toolreference/spatial-statistics/how-density-based-clusteringworks.htm

\section{Contact information:}

Klemen PRAH, Assistant Professor

(Corresponding author)

Faculty of Logistics, University of Maribor,

SI-3000, Mariborska cesta 7

E-mail: klemen.prah@um.si

Mark KMETEC, Master's Student of Logistics

Faculty of Logistics, University of Maribor,

SI-3000, Mariborska cesta 7

E-mail: mark.kmetec@student.um.si

Matjaž KNEZ, Associate Professor, Vice Dean for Economic Affairs

Faculty of Logistics, University of Maribor,

SI-3000, Mariborska cesta 7

E-mail: matjaz.knez@um.si 